\title{
Baby Spa and Baby Sleep Quality Improvement
}

\author{
Atika Yulianti \\ Department of Physiotherapy, Faculty of Health Science, University of Muhammadiyah Malang, \\ Indonesia \\ Jalan Bendungan Sutami 188A, Kota Malang, Jawa Timur, 65145 \\ *Corresponding author: tika.chu29@gmail.com
}

\begin{abstract}
Background: Sleep is one of stimulation for brain growth. Approximately $75 \%$ of growth hormone is removed when the baby is asleep. High levels of the growth hormone. This god has the task of stimulating bone and tissue growth, and regulates the body's metabolism, including the baby's brain. Sleep has a role in increasing the baby's immune to infection. If the sleep is disturbed, the levels of white blood cells in the body will decrease and result in the effectiveness of the immune system is also decreased, so the baby easily sick and growth was disrupted. Objective: The aim of this research is to know the difference of infant SPA to improve the quality of baby sleep. Method: This research uses research method with quasi experiment approach and pre post test group design. Baby sleep quality was measured using a BISQ (Brief Infant Sleep Questionnaire) questionnaire. Result: According to the result of sleep quality level at two, there is difference with value $p=0,002(p=<0,05)$. Conclusion: It was concluded that Infant Spa with intensity 3 times a day can improve sleep quality in children with severe sleep disorder.
\end{abstract}

Keywords: Baby Spa, Baby Sleep Quality, Sleep Disorders

\section{INTRODUCTION}

Sleep is a cycle of physiological processes alternating with a longer period of waking. Sleep is a top priority for infants, because at this time there is repair neuro-brain and approximately $75 \%$ growth hormone produced. Babies spend an average amount of bedtime around 60\%. The quality of baby sleep not only affects the physical development, but also the attitude the next day. Babies who sleep well without often waking up will be fit and not easy to fuss. Babies are said to experience sleep disturbances if at night sleep less than 9 hours, woke up more than 3 times and long awake more than 1 hour. During sleep the baby looks always fussy, crying and hard to sleep back (Gress et al, 2010).

Researchers at Carneigie Mellon University and University of Pensylvania found that the quantity and quality of sleep actually affects how people can become ill. The characteristics of the baby are sleepy enough, that is, he will be able to fall asleep easily at night, fit in waking, not fussy, and does not require a nap that exceeds the needs in accordance with its development (Agarwal, et al, 2000). Inadequate sleep and poor sleep quality can lead to impaired physiological and psychological balance. Physiological effects include decreased daily activity, tiredness, weakness, poor neuromuscular coordination, slow healing process and decreased immune system. While the psychological impacts include more labile emotions, anxiety, not concentration, cognitive abilities and combine the experience is lower. However, excessive sleep (especially quiet sleep) results in 
excessive energy storage. Children would less active play, so less interaction causes the development of emotion and cognitive less than optimal (Allen, 2012).

Infant spa specifically stimulates motor, improves sleep quality, and relaxation. For babies aged two months to one and a half years, emphasizing infants for swimming or baby swim in warm water pools with a maximum water temperature of 38-40 degrees may be more dependent on the baby's temperature, where the baby will swim using a buoy (Dieter, et al, 2003). In addition to having a soak function, the activity in this water to train the body functions, and move his feet and hands in the water to provide motor stimulation, and train the baby's muscles. Baby swim treatment is devoted to babies under two years who have the main goal is to stimulate the activities of the baby (Guzzetta, et al, 2011).

In massage techniques where a touch of the skin will stimulate blood circulation and will increase the energy of more oxygen waves sent to the brain to spur the circulatory system and respiration for the better. Comfortable feeling due to massage will improve the quality of sleep.

\section{METHOD}

The method used in this research is quasi experiment with pre post test group design. The independent variable of this research is baby SPA. While the dependent variable consists of sleep quality. The control variable consists of age and gender. The study was conducted on 20 subjects, using sample selection quota sampling technique. The subjects were taken from several mother schools and one of the Health Centre of the Karangplosos sub-district who fulfilled the inclusion criteria, where samples of have to in between 2 to 12 months (under 1 year) and selected mild-heavy BISQ (Brief Infant Sleep Questionnaire) categories. The sample is divided into two groups, consisting of the first group with the interval of baby Spa once a week, and the second group with a lag time of 3 days. Sleep quality is measured by BISQ.

Statistical analysis in the normality test was used to determine whether the sample used in the study came from the same population or whether the data used in the study was normally distributed or not. This analysis uses Shapiro-Wilk test using SPSS program.

Discrimination trials are conducted in groups and between groups. When the normality test yields normal distributed data, the discrimination test between the groups uses the parametric test, such as the independent sample t test. However, when the normality test yields results that are not normally distributed, the treated groups were treated using a non-parametric test, the Mann Whitney test.

\section{RESULT AND DISCUSSION}

The sample of this research is taken from mother's school and one of Health Centre in Karangploso sub-district. The sample consisted of 20 people at 2 to 12 months of age, who had sleep disorders based on BISQ (Brief Infant Sleep Questionnaire). Baby spas are done in 2 ways, in the first group given over a period of time once a week, and the second group is given for 3 times a day. 
Table 1 Results Descriptive analysis on the distribution of research subjects by Age (month) and gender

\begin{tabular}{llll}
\hline No. & Characteristics of Respondents & N & Mean \\
\hline 1 & Gender & 10 & 1.10 \\
2 & Age & 10 & 7.10 \\
\hline
\end{tabular}

Table 2 Results Normality test before and after treatment

\begin{tabular}{clcc}
\hline No. & \multicolumn{1}{c}{ Variables } & N & Significance (p) \\
\hline 1 & Sleep Quality Group 1 Before Treatment & 10 & 0.200 \\
2 & Sleep Quality Group 2 Before Treatment & 10 & 0.026 \\
3 & Sleep Quality Group 1 After treatment & 10 & 0.200 \\
4 & Sleep Quality Group 2 After treatment & 10 & 0.161 \\
\hline
\end{tabular}

Table 3 Results Analysis of differences in sleep quality groups 1 and 2

\begin{tabular}{cc}
\hline Variable & Significance $(\mathrm{p})$ \\
\hline Differences in sleep quality values in both groups & 0.002 \\
\hline
\end{tabular}

Based on the background of this study aims to prove the difference in effectiveness of infant SPA to improve the quality of baby sleep at age 2 to 12 months (under 1 year), research conducted is experimental research with quasi experimental method. The research design used was pre post test group design

The number of subjects in this study were 20 people where the sample was obtained from the mother's school and one of the Karangploso sub-district, unfortunate. Increased sleep durability showed significant differences, whereas the Sig. (2-tailed) value was $0.02(<0.05)$. The results of the discrimination test of sleep quality improvement in both groups proved that there was a difference between giving once a week and 3 times a day. This proves that infant SPAs performed with 3-day pauses more effectively improve the quality of baby's sleep. This is because the Infant Spa specifically stimulates motor, improves sleep quality, and relaxation (Kulkarni, et al, 2010).

In addition to having a soak function, the activity in this water to train the body functions, and move his feet and hands in the water to provide motor stimulation, and train the baby's muscles. Baby swim treatment is devoted to babies under two years who have the main goal is to stimulate the activities of the baby (Field \& Hernandez-Reif, 2001; Guzzetta, et al, 2011). Massage fitting SPA baby serves to help for relaxation both local and general, areas that massage reflex will occur dilation of blood vessels, where the blood circulation will increase (Dieter, et al, 2003; Guzzetta, et al, 2011). A smooth blood circulation will require more $\mathrm{O} 2$ in the blood stream an increased $\mathrm{O} 2$ need spurs the respiratory system. Touching the skin will stimulate blood circulation and will increase the energy of more oxygen waves sent to the brain so as to spur the circulatory system and respiration for the better. Comfortable feeling due to massage will improve the quality of sleep (Field et al, 2006; Gress, et al, 2010).

\section{REFERENCES}

Agarwal, KN, Gupta, A, Pushkarna, R, \& Bhargava, SK, (2000), Effects of massage and use of oil on growth, blood flow, and sleep pattern in infants, Indian Journal of Medical Research, 112, 212-217.

Allen, KA, (2012), Promoting and protecting infant sleep, Adv. Neonatal Care, 12(5), 288291. 
Dieter, JN, Field, T, Hernandez-Reif, M, Emory, EK \& Redzepi, M, (2003), Stable preterm infants gain more weight and sleep less after five days of massage therapy, Journal of Pediatric Psychology, 28(6), 403-411.

Field, T \& Hernandez-Reif, M, (2001), Sleep problems in infants decrease following massage therapy, Journal Early Child Development and Care, 168(1), 95-104.

Field, T, Diego, MA, Hernandez-Reif, M, Deeds, O \& Figuereido, B, (2006), Moderate versus light pressure massage therapy leads to greater weight gain in preterm infants, Infant Behavior and Develepoment, 29(4), 574-578.

Gress, JL, Chambers, AS, Ong, JC, Tikotzy, L, Okada, RL \& Manber, R, (2010), Maernal subjective sleep quality and nighttime infant care, Journal of Reproductive and Infant Psychology, 28(4), 384-391.

Guzzetta, A, D’acunto, M, Carotenuto, M, Berardi, N, Bancale, A, Biagioni, E, Boldrini, A, Maffei, L, \& Cioni, G, (2011), The effects of preterm infant massage on brain electrical activity, Developemental Medicine \& Child Neurology, 53(4), 46-51.

Kulkarni, A, Kaushik, JS, Gupta, P, Sharma, H \& Agrawal, (2010), Massage and touch therapy in neonates: the current evidence, Indian Pediatrics, 47(9), 771-776. 